\title{
The effects of mode of transport on sensory characteristics in indigenous Malawian chickens
}

\begin{abstract}
A study to evaluate the effects of different modes of transport on sensory characteristics in indigenous Malawian chickens was conducted at Bunda campus of the Lilongwe University of Agriculture and Natural Resources (LUANAR). The experiment used 12 birds ( 6 cocks and 6 hens) which were divided into three groups (A, B and C). In Group A, the birds were transported in crates on bicycles to the slaughter place, in Group B, the birds were hanged on a bicycle in an upside down position and transported to the slaughter place and in Group C the birds were transported to the slaughter place in an upside down position whilst in the hands of a person. For all the three groups the sensory panelists of 30 assessed, there was no significant differences $(\mathrm{P}>0.05)$ for the basic taste between the three groups. The thigh and breast of indigenous chicken meat had: pink to light red colour, slime was present in some parts, a bit wet feeling when chewing, a slow rate of muscle return and a moderate force was required for compression between the molars which are satisfactory sensory characteristics.
\end{abstract}

Volume 2 Issue 4 - 2017

Timothy Chilemba, Jonathan Tanganyika

Department of animal Science, Lilongwe University of

Agriculture and Natural Resources (LUANAR), Malawi

Correspondence: Jonathan Tanganyika, Animal Science Department, Lilongwe University of Agriculture and Natural Resources (LUANAR), Bunda campus, P.O. Box 219, Lilongwe, Malawi, Tel 265-8887699/5, 993494 774,

Email jtanganyika@gmail.com, jtanganyika@bunda.luanar.mw

Received: July 12, 2017 | Published: November 0I, 2017

Keywords: animal welfare, meat colour, breast muscle, temperature, malawian chickens

Abbreviations: SPSS, statistical product and service solutions; ANOVA, analysis of variance; MCF, molar compression force; FC, feel at chewing; RMR, rate of muscle return; LUANAR, lilongwe university of agriculture and natural resources

\section{Introduction}

Sensory evaluation is a scientific method used to measure, analyse and interpret human responses to products as perceived through their senses of touch, taste, sight, smell, or sound. ${ }^{1}$ Sensory science is often used to improve existing products and taste and color acceptance of products. There are many different types of sensory tests. Attribute difference tests ask: How does a certain quality differ between samples? Affective sensory tests ask: What is the consumer acceptance of a product? Overall difference tests ask: Does a sensory difference exist between samples? A Triangle test is a type of difference test to determine if there is a sensory difference between two products. There are also sensory tests which panelists have to be trained to detect taste thresholds (such as determining the concentration of a flavor which can be identified by the panelist when introduced to a food product) or to have trained panelists describe certain characteristics that researchers are interested in studying. Sensory tests have to be conducted under controlled conditions to reduce bias on how panelists view the products. The sensory room has to be free from distractions (sound, odors) to avoid influencing people's decisions of the product.

\section{Materials and methods}

\section{Location and study animals}

The experiment was conducted at the Lilongwe University of Agriculture and Natural Resources (LUANAR) farm from June to December 2013. A total of 21 indigenous Malawian chickens were raised for 24 weeks under intensive system.

\section{Experimental design}

12 birds ( 6 cocks and 6 hens) were randomly selected from the group and divided into three groups (A, B and C) which had equal sex numbers. Feed was withdrawn to all birds 10 hours before slaughter, but water was provided. In group A, birds were picked up in an upright position with both hands, as gently as possible and transported in crates on bicycles to the slaughter place. In group B, the birds were picked by their legs, hanged on the bicycle in an upside down position and transported to the slaughter place. The remaining birds of group $\mathrm{C}$ were also picked by their legs, but transported to the slaughter place in an upside down position whilst in the hands of a person (Table 1).

Table I Experimental design for the study

\begin{tabular}{lll}
\hline Group & Number of birds & Mode of transportation \\
\hline A & 4 & $\begin{array}{l}\text { Crates on bicycle. } \\
\text { B }\end{array}$ \\
C & 4 & $\begin{array}{l}\text { Hanged upside down on a bicycle. } \\
\text { Upside down position in the hands } \\
\text { of a person }\end{array}$ \\
\hline
\end{tabular}

The distance from the farm to the slaughter place was $4 \mathrm{~km}$ and prior to slaughter, all the birds were first stunned by allowing a physical shock to pass through the brain (mechanical method) and then were slaughtered by severing the carotid artery and jugular vein using a knife. After bleeding for $120 \mathrm{~s}$, the birds were scalded in $60^{\circ} \mathrm{C}$ water for 45 seconds and then plucked. The chickens were eviscerated and then packed in freezer bags which were afterward put in a cooler box covered with crushed ice and transported to the Nutrition Foods Laboratory at LUANAR. Immediately upon arrival in the Laboratory, all samples were unpacked, cut into two meat pieces (breast and thigh meat samples), then repacked and refrigerated at $4^{\circ} \mathrm{C}$ for sensory evaluation.

\section{Sensory evaluation}

\section{Screening of potential panellist}

30 Consumers who ate chicken meat at least once a week or more often were recruited according to their responses to a brief screening questionnaire about their; sex, age and available time to perform the 
test. The triangle test was used to screen the panelists. Three samples of sugar solution and three other samples of salt solution were presented simultaneously to the panelists. For both the two types of solutions, two samples were from the same formulation and one was from a different formulation. All three samples were presented to the panelists at once, and the panelists were instructed to taste the samples from left to right and distinguish the right one. The sugar solution had $12 \mathrm{~g}$ of sugar dissolved in water $(130 \mathrm{ml})$ thus; $0.09 \mathrm{M}$ solution and $9 \mathrm{~g}$ of sugar dissolved in $130 \mathrm{ml}$ of water thus; $0.07 \mathrm{M}$ solution and same formulation was used for the salt solution. All the solutions had different code numbers and panellists were recruited for evaluation upon correct identification of different samples that were presented to them.

\section{Training of panellists}

In a pre-tasting session, the assessors were trained to develop sensory descriptors and the definitions of the sensory attributes.

The assessors developed a vocabulary by describing differences between extreme samples and agreed on a consensus list of attributes for profiling as in Table 2.

Table 2 Definition of sensory attributes used in profiling IC samples

\begin{tabular}{lll}
\hline \multirow{2}{*}{ Attribute } & Definition & \\
\cline { 2 - 3 } & Low intensity & High intensity \\
\hline Visual colour & Light & Dark \\
Slime & No slime & Slime on all surfaces \\
Feeling at Chewing & Juicy & Dry \\
Rate of muscle return & No return & Fast return \\
Compression force for molars & Low & High \\
\hline
\end{tabular}

\section{Grilling}

After thawing, the breast and thigh fillets were cooked on racks in aluminum-lined, covered pans to an internal temperature of $76^{\circ} \mathrm{C}$ The thigh meat was cooked with skin on which was removed prior to panel presentation. The cooked meat fillets were cut to a size of $0.75 \times 0.75 \times 1.5 \mathrm{~cm}$ and were not seasoned or salted.

\section{Sample service}

The meat samples were served at 60 to $75^{\circ} \mathrm{C}$ and food warmers were used to keep the samples at above $60^{\circ} \mathrm{C}$. Each panelist was given 12 meat samples ( 6 from the thigh and 6 from the breast muscle) to evaluate visual colour, amount of slime, feeling when chewing, rate of muscle return and compression force for molars using a three-category hedonic scale (Table 3). Testing was completed in one session and a 2 minutes break was given to the consumers after tasting three samples. The order of presentation was randomized.

Table 3 Sensory attribute description and values for IC meat

\begin{tabular}{lll}
\hline Attribute & Definition & \\
& Low intensity & High intensity \\
\hline Visual colour & Light & Dark \\
Slime & No slime & Slime on all surfaces \\
Feeling at Chewing & Juicy & Dry \\
Rate of muscle return & No return & Fast return \\
Compression force for molars & Low & High \\
\hline
\end{tabular}

\section{Data analysis}

Data collected were analysed using both GenStat $14^{\text {th }}$ edition and Statistical Product and Service Solutions (SPSS) version20. Analysis of variance (ANOVA) at 5\% significance level was used to test the significant difference among the sensory attributes and chemical analysis of IC.

\section{Results}

\section{Sensory characteristics of indigenous chicken meat}

Results of visual colour, feeling at chewing, slime, rate of muscle return and force required for compression between the molars of sensory attributes scores across the twelve chicken meat samples of 30 assessors are presented in Table 4-7.

Table 4 Sensorial characteristics of IC thigh between groups (Mean \pm SE)

\begin{tabular}{llll}
\hline Parameter & Group A & Group B & Group C \\
\hline Visual colour & $1.60 \pm .675$ & $2.00 \pm .358$ & $1.77 \pm .673$ \\
Slime & $2.10 \pm .701$ & $2.05 \pm .086$ & $1.91 \pm .068$ \\
Feeling at Chewing & $1.19 \pm .018$ & $1.95 \pm .801$ & $2.01 \pm .016$ \\
Rate of muscle return & $2.38 \pm .675$ & $2.01 \pm .733$ & $2.22 \pm .076$ \\
\hline
\end{tabular}

Table 5 Sensorial characteristics of IC breast between groups (Mean \pm SE)

\begin{tabular}{llll}
\hline Parameter & Group A & Group B & Group C \\
\hline Visual colour & $2.55 \pm .308$ & $2.10 \pm .603$ & $2.05 \pm .073$ \\
Slime & $1.55 \pm .016$ & $2.35 \pm .015$ & $2.55 \pm .148$ \\
Feeling at chewing & $2.35 \pm .801$ & $2.30 \pm .213$ & $1.85 \pm .034$ \\
Rate of muscle return & $2.10 \pm .703$ & $1.65 \pm .371$ & $1.50 \pm .032$ \\
Molars Compression force & $2.65 \pm .116$ & $2.20 \pm .055$ & $2.35 \pm .019$ \\
\hline
\end{tabular}

Table 6 Sensorial characteristics of IC thigh between sexes (Mean \pm SE)

\begin{tabular}{llll}
\hline \multirow{2}{*}{ Parameter } & \multicolumn{2}{l}{ Group A } & Group B \\
\cline { 2 - 4 } & Hen & Cock & Hen \\
\hline Visual Colour & $1.93 \pm .647$ & $1.90 \pm .876$ & $1.64 \pm .674$ \\
Slime & $2.10 \pm .119$ & $2.40 \pm .699$ & $2.10 \pm .738$ \\
FC & $2.10 \pm .576$ & $2.30 \pm .823$ & $1.90 \pm .738$ \\
RMR & $1.64 \pm .399$ & $2.30 \pm .823$ & $2.30 \pm .675$ \\
\hline
\end{tabular}

Table 7 Sensorial characteristics of IC breast between sexes (Mean \pm SE)

\begin{tabular}{llll}
\hline \multirow{2}{*}{ Parameter } & \multicolumn{2}{l}{ Group A } & Group B \\
\cline { 2 - 4 } & Hen & Cock & Hen \\
\hline Visual colour & $2.00 \pm .858$ & $1.70 \pm .675$ & $1.60 \pm .843$ \\
Slime & $2.45 \pm .686$ & $1.90 \pm .568$ & $2.00 \pm .667$ \\
FC & $1.95 \pm .887$ & $2.00 \pm .816$ & $1.90 \pm .994$ \\
RMR & $2.30 \pm .733$ & $2.10 \pm .876$ & $1.70 \pm .823$ \\
\hline
\end{tabular}

\section{Visual colour}

Table $4 \& 5$ show that there was no significant difference in visual color for all the three groups of grilled IC meat with an Fprob of 0.082 . There was also no significant difference $(\mathrm{P}>0.05)$ between the cocks and the hens for both the thigh and breast meat as shown in Table $6 \&$ 7. Following the descriptive sensory analysis, assessors described the 
thigh meat from all three groups of the birds as having a pink to light red colour and the breast meat as having a pale pink colour except for the hen that was picked by its legs, but transported to the slaughter place in an upside down position whilst in the hands of a person which was described to have a slight brown to cream white colour.

\section{Feeling at chewing}

It is apparent from Table $4 \& 5$ that different modes of transport did not affect meat quality $(\mathrm{P}>0.682)$ for all the three groups of the birds. No significant difference $(\mathrm{P}>0.05)$ was also found for the feeling at chewing for cocks and the hens as evidenced in Table $6 \& 7$.

\section{Slime}

From Table $4 \& 5$, it was observed that there was no significant difference in slime on all the surfaces of the three groups of grilled IC meat with an Fprob of 0.202. There was also no significant difference ( $P>0.05$; Table $6 \&$ 7) for slime between the cocks and the hens for both the thigh and breast meat. The descriptive panel found all the twelve samples to have slime in some parts of the thigh and the breast muscle.

\section{Rate of muscle return}

From Table $4 \& 5$, it was found that the rate of muscle return was not significantly different among all the three groups of the chickens with Fprob of 0.247. Among all the three groups there was also no differences found $(\mathrm{P}>0.05)$ between the cocks and the hens thigh and breast meat as shown in Table $6 \& 7$. The trained assessors found both the thigh and breast from all the birds meat to have a slow return except for both the cock and the hen that was picked by its legs and hanged on the bicycle in an upside down position.

FC: Feel at chewing, $\mathrm{RMR}=$ Rate of muscle return. $\mathrm{MCF}=\mathrm{Molar}$ compression force

\section{Force required for compression between the molars}

The results in Table $4 \& 5$ indicate that there was no significant difference in the force required for compression between the molars values among the groups with an Fprob of 0.117 and between the chicken samples $(\mathrm{P}>0.05)$; Table $6 \& 7)$. The trained assessors observed that no high force was required for compression between the molars for all the samples but moderate force was required for compression between the molars for all groups and surprisingly low force required for compression between the molars for the thigh meat of the cock that was picked by its legs and hanged on the bicycle in an upside down position and transported to the slaughter place.

FC: Feel at chewing, $\mathrm{RMR}=$ Rate of muscle return. $\mathrm{MCF}=$ Molar compression force

\section{Discussion}

It is somehow surprising that the results from this study showed a wide variety of colour existing and this makes the current results to support previous research on meat colour ${ }^{2}$ which showed that cooked poultry can vary in colour from white to pink to tan. In meat, chemical changes also occur during cooking. Time and again, oven gases in a heated gas or electric oven react chemically with hemoglobin in the meat tissues to give it a pink tinge. Often meat of younger birds shows the most pink because their thinner skins permit oven gases to reach the flesh unlike older birds which have a fat layer under their skin, giving the flesh added protection from the gases. ${ }^{3}$ This agrees with the current findings where pink colour dominated for all thigh muscles. At the same time it could be argued that the meat ranged from white to pink because poultry grilled or smoked outdoors can be pink or white, even when all parts have attained temperatures well above 165 ${ }^{\circ} \mathrm{F}^{4}$ and not transport stress. Juiciness is a crucial sensory attribute. ${ }^{5}$ The descriptive panel found both the breast and thigh meat to have a bit wet feeling when chewing although cocks that were picked by their legs and hanged on the bicycle in an upside down position and transported to the slaughter place had a dry feeling when chewing the thigh meat and a juicy feeling when chewing the breast meat. This agrees with Fletcher ${ }^{5}$ who found that breast and thigh meat of IC under normal conditions was considered to be a bit wet when chewing This can be explained in part by the size of the samples because the fillets were a bit larger, and for this reason they had relatively more surface area in relation to muscle mass exposed to the air, which likely caused higher drip loss. ${ }^{6}$ In the present study, slime was not affected by the different modes of transport of the birds as slime formation is normally formed due to Pseudomonas spp. activity. ${ }^{7}$ In the current study, the slow return might result from the exercise which took place during the different modes of transport which might have caused a strengthening of connective tissue fiber structure ${ }^{8}$ and this can also affect fiber type proportions. Pingel \& Knust ${ }^{9}$ found that free-range ducks had more red fibers than indoor ducks, and the diameters of both red and white muscle fibers were smaller in free range birds. The diameter of the muscle fiber is positively related to the tenderness of the meat; however, the impact of exercise on meat quality is minor and ambiguous. The exercise which took place during the different modes of transport might indeed have caused a strengthening of connective tissue fiber structure ${ }^{8}$ and hence some moderate force was required for compression between the molars for the thigh and breast meat. ${ }^{10}$

\section{Conclusion}

This study aimed evaluating the effects of different modes of transport on sensory characteristics in Indigenous Chickens were it was found that mode of transport did not affect sensory characteristics in the form of visual color, slime, required force for compression between molars, rate of muscle return and feeling when chewing.

\section{Acknowledgements}

Many thanks go to Indigenous Chicken Improvement Programme (In CIP) for provision of the chickens under study. My heartfelt gratitude to Mr. J. Tanganyika, my supervisor for the encouragement, support, constructive feedback and guidance that made work easy. Finally, I thank Associate Prof. T. N. Gondwe, Mr. V. Mlotha, Professor J. P. Mtimuni, Mr. D. Chiumia and Mr. J. W. Phiri for their support and unswerving support.

\section{Conflict of interest}

The author declares no conflict of interest.

\section{References}

1. Kannan G, Terrill TH, Kouakou B, et al. Transport of goats: Effects on physiological stress responces and live weight loss. J Anim Sci. 2000;78(6):1450-1457.

2. Romans JR, Costello JW, Carson WC, et al. The Meat We Eat. Interstate publishers; 2001.

3. Lan YH, Novakofski J, McCusker RH, et al. Thermal gelation of myofibrils from pork, beef, fish, chicken and turkey. Journal of Food Science. 1995;60(5):941-945. 
4. Lawrie RA. Meat Science. 3rd ed. London: William Clovers and Sons Limited; 1997.

5. Morten C, Meilgaard B, Thomas Carr, et al. Sensory Evaluation Techniques. 3rd ed. USA: CRC Press; 1999.

6. Fletcher D L. Poultry meat quality. Journal of Poultly Science. 2002;58(2):131-145.

7. Fanatico AC, Cavitt LC, Pillai PB, et al. Evaluation of slower-growing broiler genotypes grown with and without outdoor access: meat quality. Poult Sci. 2005;84(11):1785-1790.
8. Aberle ED, Forrest JC, Gerrard DE, et al. Principles of Meat Science. 4th ed. USA: Kendall/Hunt Publication Company; 2001.

9. Pingel H, Knust U. Review on duck meat quality, Quality Poultry Meat. Netherlands: World's Poultry Science Association Beekbergen; 1993.

10. Honikel KO. Reference methods for the assessment of physical characteristics of meat. Meat Sci. 1998;49(45):447-457. 